\title{
The effect of phosphorylcoline-coated cardiopulmonary by-pass circuits on morbidity and mortality in patients with congenital open cardiac surgery
}

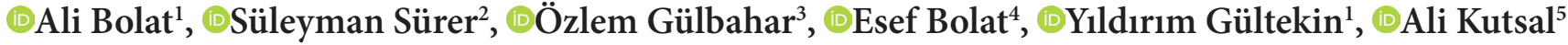 \\ ${ }^{1}$ Kırıkkale University, School of Medicine, Department of Cardiovascular Surgery, Kırıkkale, Turkey \\ ${ }^{2}$ Dışkapı Yıldırım Beyazıt Training and Research Hospital, Department of Cardiovascular Surgery, Ankara Turkey \\ ${ }^{3}$ Gazi University, School of Medicine, Department of Medical Biochemistry, Ankara, Turkey \\ ${ }^{4}$ Frrat University, School of Medicine, Department of Anesthesiology and Reanimation, Elazığ, Turkey \\ ${ }^{5}$ Dr. Sami Ulus Obstetrics and Gynecology Children's Health and Diseases Training and Research Hospital, Department of Cardiovascular \\ Surgery, Ankara, Turkey
}

Cite this article as: Bolat A, Sürer S, Gülbahar Ö, Bolat E, Gültekin Y, Kutsal A. The effect of phosphorylcoline-coated cardiopulmonary bypass circuits on morbidity and mortality in patients with congenital open cardiac surgery. J Health Sci Med 2021; 4(2): 160-165.

\begin{abstract}
Objective: Our aim in this study is to investigate the relationship between mortality and morbidity of phosphorylcholine coated oxygenator circuit used in heart-lung machine in congenital open-heart surgery operations.

Material and Method: The study was conducted in Dr. Sami Ulus Child Diseases Training and Research Hospital Cardiovascular Surgery Clinic between 2008-2009. 30 congenital heart patients were included. The patients were divided into 2 groups of 15 people. In one of the groups, a phosphorylcholine coated oxygenator circuit was used in the heart lung machine (Group P). In the other group, a standard oxygenator circuit was used (Group C).Congenital heart surgery was performed for 19 ventricular septal defects (VSD), 5 secundum atrial septal defects (ASD), 3 primum ASD, 2 mitral insufficiency and 1 discret subaortic membrane. Extubation times, intensive care and discharge times, 24-hour drainage follow-up, inotropic drug use, blood and fresh frozen plasma (FFP) transfusion amount, aspartate aminotransferase, alanine aminotransferase, creatine phosphokinase-MB, urea, blood urea nitrogen, creatinine, white cell number of platelets, lactate dehydrogenase, albumin, total protein, C-reactive protein, prothrombin time, partial thromboplastin time, fibrinogen, D-dimer, C5a and elastase levels were compared perioperatively.

Results: In the study, it was determined that the discharge time was shorter in Group P. It was found that the increase in d-dimer values with fibrinogen was less in Group P. These were found to be statistically significant $(p<0.05)$. There was no significant difference between groups in other parameters $(\mathrm{p}>0.05)$. There was no mortality in either group.

Conclusion: In this study, phosphorylcholine-coated oxygenator did not significantly reduce the inflammatory response during cardiopulmonary by-pass (CPB). There was no difference between the two groups in terms of morbitidity and mortality. However, the fact that fibrinogen values, which are the acute phase reactants, are lower than the control group and the increase in d-dimer values remain limited may be important in terms of hemocompatibility of the phosphorylcholine coated circuit.
\end{abstract}

Keywords: Phosphorylcholine coated oxygenator, congenital heart surgery, cardiopulmonary bypass, inflammation

\section{INTRODUCTION}

Cardiac surgery is a procedure widely used in congenital and adult cardiac patients all over the world (1). Openheart surgery was first performed by Gibbon (2). A cardiopulmonary bypass (CPB) machine is used to perform heart surgery in a still and bloodless environment (3). In surgery, myocardial damage and contact of patient blood with large artificial surfaces during CPB results in a strong systemic inflammatory response. The oxygenator, one of the main parts of the heart-lung machine, consists of a membrane with a large foreign surface area where oxygen and carbon dioxide are exchanged (4). Children may experience a much more severe inflammatory response during $\mathrm{CPB}$ than adults. The reason for this is that their immunological development has not yet been completed and the blood touches a larger foreign surface than the body area (5). Due to the release of 
many inflammatory cytokines by $\mathrm{CPB}$, activation of complement and coagulofibrinolytic systems is the main reason of this systemic inflammatory response $(6,7)$.The complement system consists of more than 30 plasma proteins. They are potent vasoactive anaphylotoxins interacting with each other (8). C5a, formed in the early phase of $\mathrm{CPB}$, is a potent chemotactic protein that promotes neutrophil chemotaxis, degranulation, and superoxide formation (9). Neutrophils have a strong proteolytic and cytotoxic substance stores. Azurophilic granules contain lysozyme, myeloperoxidase, cationic proteins, elastase, collagenase, proteinase-3, acid hydrolase, defensins and phospholipase. These substances, which enter the circulation from neutrophils activated by $\mathrm{C} 5 \mathrm{a}$, mediate the symptoms of "systemic inflammatory response syndrome" (SIRS) seen in CPB and cardiac surgery $(10,11)$. Neutrophil-endothelial interaction, which is formed by increasing adhesion molecules during systemic inflammatory response, has been shown as the cause of organ failure that develops after CPB (12).

This inflammatory response may cause complications such as myocardial dysfunction, respiratory failure, renal and neurological disorders, bleeding diathesis, liver dysfunction and multi-organ failure that may occur in the postoperative period (13). Foreign surfaces in the circuits used in cardiopulmonary bypass are the main cause of SIRS. Therefore, in practice, many mechanical and pharmacological methods are used to prevent this negative inflammation caused by CPB. Different surface coatings are used for the control and reduction of SIRS occurring in these methods. These are Polymethoxyethylacrylate, Albumin, heparin and heparin-polymer combinations (14).

The hemo and biocompatibility of surface coatings is very important. The hemocompatibility and biocompatibility criteria of the $\mathrm{CPB}$ circuit are as follows. It is because the circuit does not cause adverse reactions due to contact with blood. It does not cause changes in blood elements and thrombogenic phenomenon. It does not cause hemolysis or complement system activation, inflammatory response, direct or indirect toxicity, and particle separation from the circuit surface. It is chemically inert (15).

Phosphorylcholine, a biocompatible surface coating, forms a layer between the blood and the surface. In vitro and in vivo studies have shown that it reduces the inflammatory response and microbial adhesion. Thrombogenic, toxic and allergic reactions are minimal and have no immunological and carcinogenic effects $(16,17)$.
The aim of this study is to investigate the effects of phosphorylcholine-coated oxygenator circuits on morbidity and mortality by evaluating systemic inflammation in congenital heart surgery operations performed with $\mathrm{CPB}$.

\section{MATERIAL AND METHOD}

This study was approved by Dr. Sami Ulus Child Health and Diseases Training and Research Hospital Ethics Committee (date: 10.01.2008, No: 2008/05). It was performed on 30 patients who underwent congenital open heart surgery between February 2008 and July 2008 in the cardiovascular surgery clinic. Informed consent form was obtained from all patients and it was made in accordance with the Helsinki Declaration of 1964 and subsequent amendments or comparable ethical standards.

In the study, 30 congenital heart patients were divided into two groups as 15-person control and 15-person phosphorylcholine group. In the control group (Group $\mathrm{C}, \mathrm{n}=15$ ), the standard CPB oxygenator circuit (Dideco Mirandola, Italy) and in the phosphorylcholine group (Group P, $\mathrm{n}=15$ ) phosphorylcholine coated CPB circuit (Dideco Phisio Mirandola, Italy) was used. Anesthesia was induced with $15 \mathrm{mcg} / \mathrm{kg}$ fentanyl, $0.2-0.3 \mathrm{mg} / \mathrm{kg}$ midazolam and $0.1 \mathrm{mg} / \mathrm{kg}$ vecuronium and connected to the ventilator. For maintenance of anesthesia, $2 \mu \mathrm{cg} /$ $\mathrm{kg}$ fentanyl, $0.1 \mathrm{mg} / \mathrm{kg}$ midazolam (dormicum) and $0.05 \mathrm{mg} / \mathrm{kg}$ vecuronium chloride (norcuron) were added. Sevoflurane (sevorane) at approximately 1 MAC (Minimum alveolar concentration) was added if necessary. Operations were performed with a median sternotomy. Arterial cannulation was performed from the ascending aorta. Two stage venous cannulation was applied and CPB was entered. It was cooled down to 28$32^{\circ} \mathrm{C}$ according to cardiac pathologies. Cardiac arrest was achieved with antegrade hypothermic crystalloid cardioplegia. Crystalloid cardioplegia was administered at 20 -minute intervals. The amount to be administered was calculated as $20 \mathrm{ml} / \mathrm{kg}$ for the first dose and $10 \mathrm{ml} / \mathrm{kg}$ for maintenance doses. The prime solution was prepared using isolyte with Hct $30 \%$ and $50 \mathrm{mg} / \mathrm{kg}$ cefazolin was added. Age, gender, congenital heart diseases, total CPB times, crosclamping times, extubation times, intensive care and discharge times, 24-hour drainage follow-up, inotropic drug use, blood and FFP transfusion were recorded.

Blood samples were taken for aspartate aminotransferase (AST), alanine aminotransferase (ALT), creatine phosphokinase MB (CKMB isoenzyme level), urea, blood urea nitrogen (BUN), creatinine, white cell count (WBC), platelet (PLT), lactate dehydrogenase (LDH), 
albumin, total protein, C-reactive protein (CRP), prothrombin time (PT), partial thromboplastin time (aPTT), fibrinogen and D-dimer levels on preoperatively (T1), postoperatively (T2) hour and postoperative $24^{\text {th }}$ hour (T3). Blood samples for C5a and elastase were taken preoperatively (T1), before CBP (T2), before protamine administration (T3), postoperatively (T4) and at the postoperative $24^{\text {th }}$ hour (T5).

Statistical package for the social sciences (SPSS) for Windows 16.0 statistics package program was used to evaluate the data. Measuring data were expressed as mean and standard deviation. Fisher's exact test was used in quantitative data, the Mann-Whitney U test was used to compare the means of the two groups, and the Wilcoxon test was used for repeated measurements within the group. $\mathrm{P}<0.05$ was considered statistically significant.

\section{RESULTS}

Thirty patients diagnosed with congenital heart disease were divided into two equal groups; Group P and Group C. The ages of the patients participating in the study are between 1-12; mean age was calculated as $7.03 \pm 4.41$ in group $\mathrm{P}$ and $6.86 \pm 5.00$ in group $\mathrm{C}$. The demographic data of the groups are shown in Table 1. There was no statistically significant difference between the groups in terms of demographic data $(\mathrm{p}>0.05)$.

\section{Table 1. Demographic data}

\begin{tabular}{|lcc|}
\hline & Group C & Group P \\
\hline Gender $(\mathrm{F} / \mathrm{M})$ & $5 / 10$ & $6 / 9$ \\
Age $($ year$)$ & $6.86 \pm 5.00$ & $7.03 \pm 4.41$ \\
Height $(\mathrm{cm})$ & $115.27 \pm 33.37$ & $111.93 \pm 26.87$ \\
Weight $(\mathrm{kg})$ & $27.92 \pm 24.33$ & $23.44 \pm 17.36$ \\
\hline
\end{tabular}

Congenital heart disease diagnoses in Group $\mathrm{C}$ and $\mathrm{P}$ are given in Table 2. All patients consist of non-cyanotic congenital heart diseases.

\begin{tabular}{|lcc|}
\hline Table 2. Patient diagnoses & Group C & Group P \\
\hline VSD & 10 & 9 \\
Secundum ASD & 2 & 3 \\
Primum ASD & 1 & 2 \\
Mitral insufficiency & 1 & 1 \\
Discret aortic membrane & 1 & - \\
\hline VSD: Ventricular septal defect, ASD: Atrial septal defect, \\
\hline
\end{tabular}

Intraoperative and postoperative data of the groups are given in Table 3. The discharge time in Group $\mathrm{P}$ was determined to be shorter than in Group C. This is statistically significant $(\mathrm{p}<0.05)$.

\begin{tabular}{|lcc|}
\hline \multicolumn{3}{|c|}{ Table 3. Preoperative and postoperative data } \\
\hline & Group C & Group P \\
\hline CPB $(\mathrm{dk})$ & $43.93 \pm 5.05$ & $46.96 \pm 23.59$ \\
Cross clemp (min) & $26.86 \pm 15.56$ & $29.10 \pm 18.03$ \\
Extubation (h) & $8.30 \pm 8.38$ & $6.70 \pm 6.74$ \\
Intensive care (h) & $37.00 \pm 14.19$ & $29.93 \pm 8.72$ \\
Discharge (days) & $9.86 \pm 5.05$ & $7.13 \pm 2.82^{*}$ \\
Inotrope $\left(\mu \mathrm{g} \mathrm{kg} \mathrm{dk}{ }^{-1}\right.$ ) & $3.33 \pm 4.49$ & $6.00 \pm 4.70$ \\
Inotrope time (h) & $8.80 \pm 11.53$ & $13.06 \pm 11.48$ \\
Drainage amount (ml) & $227.40 \pm 119.96$ & $192.33 \pm 120.68$ \\
Given erythrocyte suspension & $50.00 \pm 154.39$ & $55.33 \pm 95.90$ \\
Given TDP (ml) & $207.66 \pm 155.83$ & $213.66 \pm 168.44$ \\
\hline CPB: Cardiopulmonary by-pass, ${ }^{*}$ p $<0.05$ \\
\hline \multicolumn{3}{|c}{} \\
\hline
\end{tabular}

Fibrinogen and D-dimer values at the 24th hour increased less in group $\mathrm{P}$ than in group C. This is statistically significant $(\mathrm{p}<0.05)$.

There was no statistically significant difference between the groups in all measurements of $\mathrm{C} 5 \mathrm{a}$ and elastase $(\mathrm{p}>0.05)$

In the within-group evaluation, a significant difference was found between postoperative and preoperative values in both groups $(\mathrm{p}<0.05)$.

\section{DISCUSSION}

Cardiac surgery mortality is higher than other surgeons. It is a surgery with high postoperative morbidity. Using $\mathrm{CPB}$ during the operation increases the inflammatory response. The main reason for this is the contact of blood with foreign surfaces. Complications such as rhythm disturbance, ventricular dysfunction requiring inotropic support, infection, gastrointestinal dysfunction, acute lung injury, and renal failure may develop. Increased systemic inflammatory response to surgical trauma may cause many postoperative complications (18).

In the pediatric age group, age-related differences in inflammatory response with immature organ systems may lead to increased damage due to CPB. In addition, larger extracorporeal circulation volume compared to body surface area in this patient group may result in more complications related to CBP $(19,20)$.

The most severe consequence of the inflammatory response is multiple organ dysfunction and death. Mild inflammatory responses do not cause severe organ dysfunction requiring intensive care, but increase hospital stay and cost. Systemic inflammatory response is a multifactorial event and has secondary effects on damaged and intact tissue. Proinflammatory mediators can have beneficial effects on many organ systems as well as harmful effects. Tissue damage, endotoxemia and contact of blood with a foreign surface during CPB are the main causes that lead to systemic inflammatory response (21). For this reason, different surface coatings are used to control and reduce the resulting SIRS. 
Zwaal at al. (22) showed that the outer surfaces of the erythrocyte membranes are antithrombogenic and that the phospholipids on the cell membrane are in asymmetric distribution. Lipids containing phosphorylcholine cell is found to be concentrated in a bilayer membrane outer layer. Chapman et al. (23) succeeded in binding methacrylolphosphorylcholine/lauryl-methacrylate co-polymers to metal and synthetic surfaces and the term "biomembrane mimicry" first appeared for phosphorylcholine-coated surfaces. In vitro and animal experiments have shown that phosphorylcholine coated artificial polymers, which are one of the surface coating technologies used to improve the hemo and biocompatibility of artificial devices, have thrombogenic resistance. These polymers exhibit minimal plasma protein and platelet adhesion and are used in contact lenses and CPB circuits (24-26).

In another experimental study conducted by De Somer et al. (27) they stated that C5a levels slightly increased in phosphorylcholine-coated circuits. In our study, an increase was observed in the post-bypass period, and results similar to preoperative values were obtained in later values. In a study conducted by Draaisma et al. (28) in 28 neonatal and infants, they compared phosphorylcholine-coated circuits with circuits without surface coating. When they evaluated the groups in terms of complement factor $\mathrm{C} 3 \mathrm{~b} / \mathrm{c}$, elastase, CRP values, duration of intensive care, ventilation duration, body temperature and inotropic medication, they stated that there was no difference between the groups. In our study, there was no difference in C5a and elastase results between groups ( $p>0.05)$. However, when the groups were compared within themselves, we found that it was higher in the postoperative period. This indicates that there is inflammation during the surgery. However, we can say that there is no difference between the groups in terms of inflammatory severity, which is consistent with the study of Draaisma et al. (28).

In their study on 39 high-risk patients, Pappalardo et al. (29) stated that the platelet count, soluble CD40 ligand, fibrinogen, antithrombin, D-dimer, prothrombin fragments and free hemoglobin values and postoperative bleeding, the amount of blood administered and clinical results were similar. Nevertheless, they stated that when phosphorylcholine coated circuits are used together with tracamide acid, intraoperative thrombin formation can be improved and platelet, fibrinogen and antithrombin consumption may be reduced. In our study, we found that the increase in fibrinogen and $\mathrm{D}$-dimer values among the parameters. We used to evaluate the bio and hemocompatibility of phosphorylcholine-coated circuits increased significantly less in group P. This is important for hemocompatibility, but there was no difference in the amount of drainage between the groups. There was also no difference in the use of blood and FFP ( $p>0.05)$. On the other hand, De Somer et al. (30) found no difference in the formation of hemolysis and thrombin formation between the phosphorylcholine coated group and the non-surface coated group, however, they stated that the amount of blood loss was 30\% less in the phosphorylcholine coated group. Again, they reported that the most beneficial effect of phosphorylcholinecoated circuits was on thrombocytes and therefore reduced blood loss. Kirshbom et al. (31) showed that phosphorylcholine and heparin coated circuits were not different from circuits without surface coating in terms of platelet count, beta-thromboglubulin values, thromboelastographic measurements of platelet function, and postoperative bleeding amounts. They stated that clinical results did not change in pediatric cardiac surgery. Thrombocytopenia is due to dilution, platelet adhesion to lines, aggregation, activation and removal of damaged platelets by the reticuloendothelial system. After CPB, the platelet count is $30-50 \%$ below the preoperative level. (32). In our study, significant decreases in platelet values were observed, but no difference was found between the groups. Again, in the comparisons between groups, there was a significant prolongation in postoperative values according to preoperative PT and aPTT values, but no difference was found between groups.

Harig et al. (33) stated that phospholipid-coated CPB circuits have beneficial effects on clinical parameters such as ventilator and ICU stay in pediatric patients. Nevertheless, they reported that it should be confirmed by studies involving many patients. In our study, there was no difference between the groups in terms of length of stay in the intensive care unit.

Urea, BUN and creatinine parameters were measured to evaluate renal functions. Serum creatinine and creatinine clearance is the most commonly used and practical method in clinical use (34). In our study, although the postoperative creatinine value was significantly higher than the preoperative value in the control group, it was within normal limits. Acute or chronic renal failure was not observed.

Liver enzymes may increase slightly in the postoperative period, and mild icter may be observed in $10-20 \%$ of the cases. In the majority of cases with icterus, the etiology is hemolysis rather than liver (35). In the study, Although there was no difference between the groups in terms of AST, ALT, LDH, total protein, albümin and CKMB values, there was a significant difference in these parameters compared to the preop values in the measurements within the group. This is a result of the surgery and CBP's inflammatory response in the liver. 
There was no statistically significant difference between the groups in terms of X-clamp and CBP times. All of the patients in the study consisted of isolated cogenital heart disease. This resulted in short X-clamp and CBP times. This caused a limitation of the study. Inclusion of complex congenital heart patients in the study may increase the mean CBP duration and inflammatory response (36). We think that better data can be reached to measure inflammation in terms of evaluating biocompatibility.

\section{Limitation of the Study}

All patients in the study consisted of non-cyanotic cogenital heart disease. This resulted in shorter crossclamp and CBP times. Including cyanotic groups in the study and conducting more studies on more patients can be more accurate in terms of inflammation.

\section{CONCLUSION}

Phosphorylcholine coated circuits do not significantly reduce complement and neutrophil activation during $\mathrm{CPB}$. Because the artificial surface does not trigger the inflammation that occurs after CPB. It depends on many factors, as noted in other studies. We believe that additional applications are required in order to control inflammation in CPB. On the other hand, we think that the lower fibrinogen values, which are the acute phase reactants, and the limited rise in $\mathrm{D}$-dimer values, the short hospital discharge period, the shorter extubation and intensive care stay, although not statistically significant, may be important in terms of biocompatibility and hemocompatibility.

\section{ETHICAL DECLARATIONS}

Ethics Committee Approval: This study was approved by Dr. Sami Ulus Child Health and Diseases Training and Research Hospital Ethics Committee (date: 10.01.2008, No: 2008/05).

Informed Consent: All patients participating in the study have signed the informed consent form.

Referee Evaluation Process: Externally peer-reviewed.

Conflict of Interest Statement: The authors have no conflicts of interest to declare.

Financial Disclosure: There is no person/organization that financially supports the study.

Author Contributions: The authors declared that they have all participated in the design, execution, and analysis of the paper, and that they have approved the final version.

\section{REFERENCES}

1. Zahler S, Massoudy P, Hartl H, Hähnel C, Meisner H, Beckeret BF. Acute cardiac inflammatory responses to post ischemic reperfusion during cardiopulmonary bypass. Cardiovasc Res 1999; 41: 722-30.

2. Gemalmaz H, Gültekin Y, Hasanov Y. Yurtdışında yeni kurulan kalp merkezindeki sonuçlar. AJHM 2020; 3: 11-7.

3. Siregar S, Groenwold RHH, De Mol BAJM, et al. Evaluation of cardiac surgery mortality rates: 30 -day mortality or longer follow up? Eur J Cardio Thoracic Surg 2013; 44: 875-83.

4. McGiffin DC, Kirklin Ki. Cardiopulmonary bypass for cardiacsurgery. in Sabiston DC, Spencer FC. Surgery the Chest. 61h ed, yol II, Philadelphia: WB Saunders, 1256-71, 1995.

5. Brix-Christensen V. The systemic inflammatory response after cardiac surgery with cardiopulmonary bypass in children. Acta Anaesthesiol Scand 2001;/45:/671-9.

6. Butler J, Rocker GM, Westaby S. Inflammatory response to cardiopulmonary bypass. Ann Thorac Surg 1993; 55: 552-9.

7. Casey LC. Role of cytokines in thepathogenesis of cardiopulmonary induced multisystem organ failure. Ann Thorac Surg 1993; 56: 92 6.

8. Walport MJ. Complement. N Engl J Med 2001; 344: 1058.

9. Mansuroğlu D, Kirali K, Yakut C. Kardiyopulmoner bypass sırasındaki enflamatuvar yanıt: hücresel yanıt, enflamasyonun diğer mediyatörleri, akut enflamasyonun kontrolü. Türkiye Klinikleri Kalp Damar Cerrahisi Derg 2004; 5: 183-96.

10. Ilion MK. Langlon PE. Taylor ML, et al. Differential expression of neutrophil adhesion molecules during coronary artery surgery with cardiopulmonary bypass. J Thorac Cardiovasc Surg 1999; 118: 930-7.

11. Mair P. Mair J. Seibt I Furtwaengler W, Balogh D. Plasma elastase concentrations and pulmonary function after cardiopulmonary bypass. J Thorac Cardiovasc Surg 1994; 108: 184-5.

12. Windsor AC, Mullen PG, Fowler AA, Sugerman HJ. Role of theneutrophil in adult respiratory distress syndrome. $\mathrm{Br} \mathrm{J}$ Surg1993; 80: 10-7.

13. Paparella D, Yau TM, Young E. Cardiopulmonary bypass induced inflammation; pathophysiology and treatment. An update. Eur J Cardiothorac Surg 2002; 21: 232-44

14. Wan S, Le Clerc JL, Vincent JL. Inflammatory response to cardiopulmonary bypass, mechanisms involved and possible therapeutic strategies. Chest 1997; 112: 676-92.

15. Günaydin E. Emerging Technologies in biocompatible surface modifying additives quest for physiologic cardiopulmonary bypass. Curr Med Chem Cardiovasc Hematol Agents 2004; 2: 187-96.

16. De Somer F, François K, vanOeveren W, et al. Phosphorylcholine coating of extra corporeal circuits provides natural protection against blood activation by the material surface. Eur J Cardiothorac Surg 2000; 18: 602-6.

17. VonSegesser LK, Mihaljevic T, Tönz M, Leskosek B, Pei P, Turina M. Heparin surface coated hard shell venous reservoirs: experimental evaluation exvivo. Int J Artif Organs. 1994; 17: 651-56.

18. Larmann J, Theilmeier G. Inflammatory response to cardiac surgery: cardiopulmonary bypass versus non-cardiopulmonary bypass surgery. Best Pract Res Clin Anaesthesiol 2004; 18; 425-38.

19. Kozik DJ, Tweddell JS. Characterizing the inflammatory response to cardiopulmonary bypass in children. Ann Thorac Surg 2006; 81: $2347-54$

20.Boldt J, Osmer C, Linke LC, Dapper F, Hempelmann G. Circulating adhesion molecules in pediatric cardiac surgery. Anesth Analg 1995; 81: 1129-35 
21.Çelebioğlu B, Özer E. Kardiyopulmoner by-pass ve sistemik inflamatuvar yanit. Hacettepe Tip Derg 2004; 35: 18-26.

22.Zwaal RFA, Comfurius P, vanDeenen LLM. Membrane assymmetry and blood coagulation. Nature 1977; 268: 358-60.

23. Yianni YP. Biocompatible surfaces based upon biomembrane mimicry. In: Quinn PJ, Cherry RJ, editors. Structural and Dynamic Properties of Lipids and Membranes, London: Portland Press Ltd, 1992, 187-216.

24. VonSegesser LK, Mihaljevic T, Tönz M, Leskosek B, Pei P, Turina M. Heparin surface coated hard Shell venous reservoirs: experimental evaluation exvivo. Int J Artif Organs. 1994; 17: 65156.

25.Campbell EJ, O'Byrne V, Stratford PW, et al. Biocompatible surfaces using methacryloylphosphorylcholine laurylmethacrylate copolymer. ASAIO J 1994; 40: 853-7.

26. Wendel HP, Ziemer G. Coating-techniques to improve the hemocompatibility of artificial devices used for extracorporeal circulation. Eur J Cardiothorac Surg 1999; 16: 342-50.

27.De Somer F, Van Belleghem Y, Foubert L, et al. In vivo evaluation of a phosphorylcholine coated cardiopulmonary bypass circuit. J Extra Corpor Technol 1999; 31: 62-6.

28. Draaisma AM, Hazekamp MG, Anes N, et al. Phosphorylcholine coating of bypass systems used for young infants does not attenuate the inflammatory response. Ann Thorac Surg 2006; 81: 1455-9.

29. Pappalardo F, DellaValle P, Crescenzi G, et al. Phosphorylcholine coating may limit thrombin formation during high-risk cardiacsurgery: a randomized controlled trial. Ann Thorac Surg 2006; 81: 886-91.

30. De SF, Van BY, Caes F, et al. Phosphorylcholine coating offers natural platelet preservation during cardiopulmonary bypass. Perfusion 2002; 17: 39-44.

31.Kirshbom PM, Miller BE, Spitzer K, et al. Failure of surfacemodified bypass circuits to improve platelet function during pediatric cardiac surgery. J Thorac Cardiovasc Surg 2006; 132: 675-80.

32.Zilla P, Fasol R, Groscurth P, Klepetko W, Reichenspurner H, Wolner E. Blood platelets in cardiopulmonary bypass operations. J Thorac Cardiovasc Surg 1989; 97: 379.

33. Harig F, Cesnjevar R, Lindemann Y, Bumiller L, Singer H, Weyand M. Phosphorylcholine-coated cardiopulmonary bypass in paediatric cardiac surgery improves biocompatibility: reduced contact activation and endothelin-1 release. Critical Care 2001, 5: 14 .

34. Bove T, Calabro MG, Landoni G, et al. The incidence and risk of acute renal failure after cardiac surgery. J Cardiothorac Vasc Anesth 2004; 8: 442-45.

35. Collins JD, Ferner R, Murray A, et al. Incidence and prognostic importance of jaundice after cardiopulmonary bypass surgery. Lancet 1993; 1: 1119.

36. Florens E, Salvi S, Peynet J, et al. Can statins reduce the inflammatory response to cardiopulmonary bypass? A clinical study. J Card Surg 2001; 16: 232-9. 